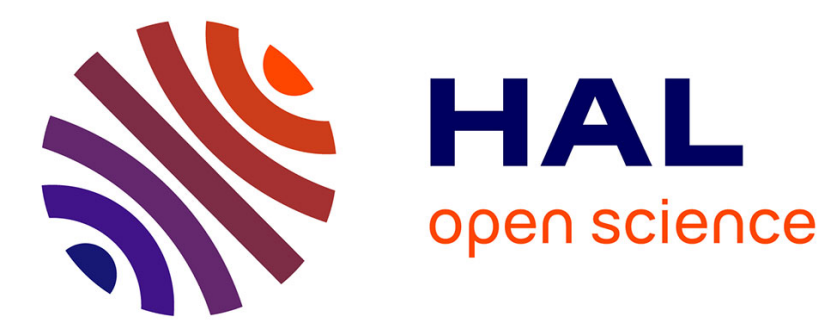

\title{
Unconscious task set priming with phonological and semantic tasks.
}

Sébastien Weibel, Anne Giersch, Stanislas Dehaene, Caroline Huron

\section{To cite this version:}

Sébastien Weibel, Anne Giersch, Stanislas Dehaene, Caroline Huron. Unconscious task set priming with phonological and semantic tasks.. Consciousness and Cognition, 2013, 22 (2), pp.517-527. 10.1016/j.concog.2013.02.010 . inserm-00816715

\section{HAL Id: inserm-00816715 https://www.hal.inserm.fr/inserm-00816715}

Submitted on 22 Apr 2013

HAL is a multi-disciplinary open access archive for the deposit and dissemination of scientific research documents, whether they are published or not. The documents may come from teaching and research institutions in France or abroad, or from public or private research centers.
L'archive ouverte pluridisciplinaire HAL, est destinée au dépôt et à la diffusion de documents scientifiques de niveau recherche, publiés ou non, émanant des établissements d'enseignement et de recherche français ou étrangers, des laboratoires publics ou privés. 


\section{Unconscious Task Set Priming With Phonological and Semantic Tasks}

\section{Author names and affiliations}

Sébastien Weibel ${ }^{1}$, Anne Giersch ${ }^{1}$, Stanislas Dehaene $^{2}$ and Caroline Huron ${ }^{2}$

1. INSERM, Department of Psychiatry, Centre Hospitalier Régional Universitaire, Strasbourg, France

2. INSERM, Cognitive Neuroimaging Unit, Gif sur Yvette, France

\section{Corresponding author}

Sébastien Weibel, INSERM, Department of Psychiatry, Centre Hospitalier Régional Universitaire, 1 place de l'hôpital, Strasbourg, 67091 France. Telephone: +33388116445. Fax: +33388116446 .

E-mail: weibelse@gmail.com

Word count: 6477 words 


\begin{abstract}
Whether unconscious stimuli can modulate the preparation of a cognitive task is still controversial. Using a backward masking paradigm, we investigated whether the modulation could be observed even if the prime was made unconscious in $100 \%$ of the trials. In two behavioral experiments, subjects were instructed to initiate a phonological or semantic task on an upcoming word, following an explicit instruction and an unconscious prime. When the SOA between prime and instruction was sufficiently long ( $84 \mathrm{~ms}$ ), primes congruent with the task set instruction led to speedier responses than incongruent primes. In the other condition (36 ms), no task set priming was observed. Repetition priming had the opposite tendency, suggesting the observed task set facilitation cannot be ascribed solely to perceptual repetition priming. Our results therefore confirm that unconscious information can modulate cognitive control for currently active task sets, providing sufficient time is available before the conscious decision.
\end{abstract}

Keywords: Consciousness; Masking; Cognitive control; Task switching; Semantic judgment; Phonological judgment 


\section{Unconscious Task Set Priming With Phonological and Semantic Tasks}

\section{Introduction}

It is widely acknowledged that information not consciously perceived can influence our perception and behavior, and subliminal priming has been demonstrated at visual, semantic and motor levels (for a recent review, see Dehaene \& Changeux, 2011). Non-conscious information can modulate performance in many cognitive tasks, eg. object recognition (Stoerig \& Cowey, 1997), extraction of the meaning of words (Gaillard et al., 2006; Naccache \& Dehaene, 2001; Van den Bussche, Notebaert, \& Reynvoet, 2009), categorization (Van den Bussche \& Reynvoet, 2007), emotional processing (Whalen et al., 1998), action planning and execution (Binsted, Brownell, Vorontsova, Heath, \& Saucier, 2007). Recently, it has been reported that monetary rewards affected subjects' motivation in a force task (Pessiglione et al., 2007), a finger-tapping task (Bijleveld, Custers, \& Aarts, 2010, 2012) and a switch task (Capa, Bouquet, Dreher, \& Dufour, 2012) even though participants were unaware of the reward.

However, the extent to which non-conscious stimuli influence high-order control functions remains controversial in cognitive psychology. Cognitive control processes have traditionally been considered to be based on voluntary control and to depend on conscious decision-making and awareness. As such, they have been contrasted with unconscious, automatic information activation. According to the global neuronal workspace framework (Dehaene, Changeux, Naccache, Sackur, \& Sergent, 2006), top-down strategic processes can influence unconscious processing (Merikle, Joordens, \& Stolz, 1995; Naccache, Blandin, \& Dehaene, 2002; Van den Bussche, Segers, \& Reynvoet, 2008), but the possibility of an effect 
of non-conscious stimuli on cognitive control processes is not explicitly included in the model (Dehaene \& Naccache, 2001). ${ }^{1}$

Recent findings suggest subliminal stimuli can affect high-order cognitive processes such as inhibitory control or task-setting. In a go/no go task, for instance, non-conscious "stop" signals slow down motor responses. This inhibitory control, which occurs unbeknown to the subject, is associated with a frontal activity typically related to response inhibition in both electroencephalographic (Hughes, Velmans, \& Fockert, 2009; van Gaal, Ridderinkhof, Fahrenfort, Scholte, \& Lamme, 2008) and functional magnetic resonance imaging (fMRI) (Van Gaal, Ridderinkhof, Scholte, \& Lamme, 2010) studies. These findings are evidence that inhibitory control can be triggered unconsciously.

Another set of studies has addressed the activation of task sets by masked stimuli that do not reach consciousness (Lau \& Passingham, 2007; Mattler, 2003; Reuss, Kiesel, Kunde, \& Hommel, 2011). The concept of task set assumes we can adopt a particular configuration of our cognitive system to perform a given task (Rogers \& Monsell, 1995). Mattler et al. instructed participants to indicate either a sound's timbre (piano versus marimba) or its pitch (high versus low). A shape (task cue) indicated which task they were to perform, with diamonds denoting the pitch task and squares the timbre task. Before the fully visible task cue was presented, there was a prime in the shape of either a diamond or square. The task cue acted as a metacontrast for the prime so that the latter was either visible or invisible depending on the delay between prime and task cue onsets. The results signaled a congruency effect for subliminal primes: participants responded faster when the shapes of the prime and cue were the same than when they were different. These findings suggested that subliminal primes triggered the establishment of a cognitive task set which shortened the preparation time for the task when the visible cue occurred. 
Using a similar paradigm in a fMRI study, Lau and Passingham (2007) reported that, relative to congruent trials, in incongruent trials increased activity was observed in brain regions associated with the task cued by the subliminal prime, whereas reduced activity was reported in brain regions associated with the task cued by the visible instruction. These results demonstrated that the task-related network can be modulated by subliminal information.

There are methodological concerns surrounding these important studies which could undermine their conclusions. Firstly, in all of them the absence of awareness of masked primes cannot be taken for granted in all subjects. In the Mattler study (2003), for example, participants' performance when they had to identify the shapes of the subliminal primes was at best only marginally different from chance, around $55 \%\left(d^{\prime}=0.28\right)$, and in the worst case, close to $60 \%$ (i.e. above-chance). In the Lau and Passingham study (2007), discriminability in the low-visibility condition was lower $\left(\mathrm{d}^{\prime}=0.05\right)$, but the difference in relation to the conscious condition was quite small $\left(\mathrm{d}^{\prime}=0.26\right)$, with the latter result equivalent to the Mattler unconscious condition. It is possible these results are due to the choice of masking by metacontrast. Secondly, the presence of conscious primes in the same block as masked primes might have had an effect on the visibility of the prime, by creating an expectation of a stimulus, which has been shown to speed information processing (Vangkilde, Coull, \& Bundesen, 2012), and might have facilitated the priming effect (Naccache et al., 2002). All in all, it still seems necessary to check whether task-set priming effects can be replicated in strict conditions where subjects are unaware of the primes. To that end, we used a backward masking paradigm in which a single letter displayed only briefly was followed 24 ms later by a mask consisting of letters surrounding the previous letter location (Del Cul, Baillet, \& Dehaene, 2007; Del Cul, Dehaene, \& Leboyer, 2006). It has previously been shown that both objective measures (proportion of primes correctly identified) and the subjective visibility of the primes reported by participants indicated they were not aware of the presentation of the 
primes under these experimental conditions. Furthermore, unlike all previous studies, which combined trials with conscious primes with trials with masked primes, we did not include any trials with conscious primes.

Another methodological issue concerns the double dissociation between priming effect and visibility reported in the study by Lau and Passingham (2007): the priming effect was maximal when the prime visibility was minimal but disappeared when participants consciously perceived the prime (see also Schmidt \& Vorberg, 2006). The absence of an effect of a visible prime on the task set selection could be due to an excessively too short delay between the prime and the task cue in the conscious condition (16 ms) compared with the subliminal condition ( $83 \mathrm{~ms}$ ). It has already been shown that the efficiency of visible primes generally increases as a function of the prime-target delay (Kouider \& Dehaene, 2007). Two factors were therefore confounded: the visibility of the prime and the delay between prime and instruction. The confound is due to the use of metacontrast masking characterized by a U-shaped visibility curve as the delay between prime and instruction increases. In the present study we examine the impact of this delay manipulation while keeping constant the SOA between prime and mask.

The purpose of the present study was to provide more evidence proving that a subliminal prime could initiate a task set. We designed a different masking procedure to overcome the methodological issues raised by the study by Lau and Passingham (2007). First of all, we were intent on making sure the participants really were unaware of the prime. Even if it is difficult to demonstrate statistically that visibility is exactly zero, it is known that metacontrast masking rarely produces complete masking at any level of SOA (Francis, 1997). Here, we used backward masking which allows no visibility of the prime, as previously shown by objective performance and subjective ratings (Del Cul et al., 2007, 2006). Secondly, primes were subliminal in all trials to avoid any clue that might have modified the 
participants' attentional focus. Thirdly, to study the impact of the delay between the subliminal prime and the mask, we compared two intervals between prime and instruction in two different experiments. Fourthly, to gain a better understanding of the links between the repetition priming and task set priming, we used both tasks in the same experimental procedure. Each participant performed a task set priming task, followed by a repetition priming task (motor response priming).

\section{Experiment 1}

\subsection{Methods}

2.1.1 Participants. Twenty students from the University of Strasbourg (16 women, 4 men), aged between 19 and $44(\mathrm{M}=24.7, \mathrm{SD}=5)$, took part in the experiment. Their level of education ranged from 12 to 16 years $(\mathrm{M}=14.8, \mathrm{SD}=1.47)$. All of them had normal or corrected-to-normal visual acuity, verified with the help of the Freiburg Visual Acuity Test (Bach, 2006). Each participant took part in one 90 minute session. Their informed written consent was obtained prior to the study, in accordance with the recommendations set out in the Helsinki Declaration.

2.1.2 Equipment. Participants were seated $60 \mathrm{~cm}$ from the stimulus presentation screen in a dimly lit room for the duration of the experimental session. The behavioral tasks were presented using E-prime version 1.1 (Psychology Software Tools, Inc. Sharpsburg, PA). The screen refresh rate was set at $85 \mathrm{~Hz}$ (screen refresh every $11.8 \mathrm{~ms}$ ). Responses were collected with a serial response box (Psychology Software Tools, Inc. Sharpsburg, PA). 
2.1.3 Stimuli. In each trial, the prime was displayed first, and then followed by a mask, the instruction letter, and the target word. The prime was a letter (A or S, Arial font, size: $\left.1.25^{\circ}\right)$ presented in one of four positions $\left(2.3^{\circ}\right.$ above or below and $2.3^{\circ}$ to the right or left of the central fixation cross).

The mask consisted of 4 letters surrounding the previous position of the prime (two E above and below, and two $\mathrm{M}$ on left and right). The mask served to render the prime invisible. The instruction consisted of a letter (A or S), the same size as the prime, but in bold font and colored blue. It was presented in the square delimited by the mask furthest from the fixation cross. NB: As a result, the instruction letter never appeared in exactly the same location as the prime (Figure 1).

2.1.4 Procedure. The participants completed a three-phase procedure. They started with a task set priming task, which involved applying one of two strategies according to an instruction letter that could change with every trial. Secondly, they performed a repetition priming task, where they had to identify the letter representing the instruction, which in this task is the target letter. Thirdly, they were told about the presence of a congruent or incongruent invisible prime before performing a prime identification task.

Task set priming. An instruction letter presented on the screen indicated the type of judgment the subjects would have to emit on the following word. In the case of an "S" instruction (like "Syllabic") the participants had to make a phonological judgment: they had to decide whether or not the word was bisyllabic. In the case of an " $\mathrm{A}$ " instruction (like "Animate"), they had to make a semantic judgment: they had to decide whether the word corresponded to something living or non-living. The volunteers were told they had to prepare the task set quickly once they had seen the instruction. They were not told about the presence of an invisible prime. 
Figure 1 illustrates the experimental stimuli and procedure. The fixation cross was displayed throughout the session. In each trial, the prime was presented for $12 \mathrm{~ms}$. After a 24 ms delay during which the screen remained blank, the mask and instruction letter appeared together for $152 \mathrm{~ms}$, in the same quarter of the screen as the preceding prime. Thus, the stimulus onset asynchrony (SOA) between prime and mask, as well as between prime and instruction, was $36 \mathrm{~ms}$. After a delay of $156 \mathrm{~ms}$ during which the screen remained blank (344 ms after the onset of the prime) the target word was presented at the center of the screen for $750 \mathrm{~ms}$. The next trial began 3 seconds after the word offset.

The volunteers responded "yes" by pressing a key with their left index finger and "no" by pressing a key with their right index finger. They were instructed to respond as accurately and as quickly as possible, within 3 seconds of the word onset.

Each participant completed four blocks of 96 trials each (384 trials). In half the trials, the task was phonological, and in the other half, semantic. Within each of these conditions, the prime was congruent with the instruction in half the trials, and incongruent in the other half. In our pilot studies, switching instructions between consecutive trials seemed to be an important factor to control and was taken into account in the study design. Trials with and without task switching between consecutive trials (switch vs. no-switch) were displayed in equal proportions. The fillers, i.e. the first trial in a sequence of two trials, were not included in the statistical analyses. The participants were not told about the fillers, and the temporal course of fillers and target trials was exactly the same. Conditions of task, congruency, task switching, and the position of the stimuli (a total of 32 possible combinations) were represented in the same proportions. The same word was never repeated between two consecutive trials.

Twenty-four different French nouns were used. Their occurrence ranged from 0.68 to 56 per million (Lexique Database: New, Pallier, Ferrand, \& Matos, 2001). The words were 
either bi- or trisyllabic, and denoting something either animate or inanimate, in equal proportions. Words that were ambiguous in terms of syllables or meaning were excluded. We chose a small number of words to accelerate decision-making and reduce the variability of RTs.

To avoid unwanted response strategies, the responses were systematically incongruent in both tasks: all trisyllabic words corresponded to something animate, and bisyllabic words to something inanimate. Unbeknown to the participants, the selection of words with intrinsic response incongruence ("yes" for one task and "no" for the other) avoids automatic responses based solely on their memory of stimulus-response pairs. We checked to make sure subjects did not consciously employ a strategy of using the same judgment in all cases and reversing the responses according to the instructions given. A questionnaire filled in at the end of the procedure was designed specifically to hunt out such a strategy. The questions were open to begin with, and then steadily more targeted to focus on the strategies used during the procedure. Three subjects had noticed that bisyllabic words were inanimate and trisyllabic words animate, leading them to use the afore-mentioned strategy. These three participants were excluded from the analyses.

The experiment was divided into four 12-minute runs, between which the participants were allowed a 5-minute rest to ensure their sustained attention. A training session beforehand, consisting of 100 trials, allowed us to check whether or not the instructions were properly understood. The instructions were presented on the computer screen and oral explanations were also given.

Repetition priming. The stimuli (prime, mask and instruction, and word) and their temporal course were identical to the task set priming procedure, including the use of filler trials. Only the task was different. Participants were asked to focus their attention on the instruction letter, which is the target in this phase, and to press, as quickly as possible, the 
right button in the case of an " $\mathrm{A}$ " letter and the left button in the case of an "S" (counterbalanced between subjects). Participants completed one block of 128 trials.

Measurement of prime awareness. Following the two priming tasks, participants were asked whether they had noticed anything other than the $\mathrm{E}$ and the $\mathrm{M}$ in the mask. They were then told that a prime had been presented and were asked once again whether they had noticed anything before the mask and the instruction letter. Afterwards, they were shown the exact stimulus sequence in slow motion and were asked if they recognized having seen any of the primes during the priming task. Finally, the prime identification task was conducted, consisting of one block of 128 trials. The stimuli and time course were the same as in the two previous tasks. Participants were asked to identify the prime, and to respond by pressing one of the two buttons (counterbalanced between subjects), even if they were unable to see it (forced choice). Lastly, they were asked whether or not they felt they were able to see the masked primes during the prime identification task.

\section{< Insert Figure 1 about here >}

2.1.5 Statistical analyses. We conducted ANOVAs with repeated measures, prime congruency (prime and target identical vs. different), task (semantic vs. syllabic), and switch (task instruction identical to the previous trial vs. different) as within-group factors for the task set priming session, and prime congruency and switch as within-group factors for the repetition priming session. Analyses were performed on median correct response times. For the prime detection task, accuracy was analyzed with respect to prime recognition and compared to the chance level of $50 \%$ using a t-test. The signal detection theory was used to calculate the d' index (index of signal detectability). 


\subsection{Results}

Three subjects pointed out that bisyllabic words were inanimate or vice versa, which had lead them to respond always with a semantic task set and to reverse their response in the case of an "S" instruction. These three participants were excluded from the analyses. NB: For the sake of clarity, the results are presented in reverse order to the order in which the three tasks were administered.

2.2.1 Awareness of primes. None of the 17 participants reported having seen the prime letter before the target during the priming experiments. When informed about the presence of the primes, 3 subjects thought they might have seen a slight blink, but were unsure, and no one thought it was a letter. No participants reported having seen the prime in the prime identification task. They spontaneously reported that they were not confident about their estimations and were only guessing. Their performance in the forced-choice task ranged from $41 \%$ to $59 \%$ and averaged $49.7 \%$, which was not significantly different from chance, $t(16)=-$ $0.24, p=0.81$. The mean value of d' was -0.013 , which was not significantly different from 0 $(\mathrm{t}(16)=-0.24, \mathrm{p}=0.82)$. Mean accuracy for the 3 subjects who detected a flash was $50 \%$ and $d$ ' was 0.01 .

2.2.2 Repetition priming. Figure 2 shows the median RTs averaged across subjects for each repetition priming condition. We found a significant main effect of prime congruency on reaction times $\left(\mathrm{F}(1,16)=64.5, \mathrm{p}<0.001, \eta^{2}=0.80\right)$. Subjects were quicker to identify the target letter (instruction) when the prime letter was the same as the instruction (442.2 ms versus $482.8 \mathrm{~ms}$ when it was different). The mean size of the effect was $40.6 \mathrm{~ms}$ ( $8.7 \%$ of the median RT). All subjects displayed a repetition priming effect. A significant interaction between congruency and switch $\left(F(1,16)=4.7, p<0.05, \eta^{2}=0.23\right)$ indicated that the priming effect was greater when the instruction letters were the same between two subsequent trials $(53.8 \mathrm{~ms})$, than when there was a switch $(31.2 \mathrm{~ms})$. 
2.2.3 Task set priming. Figure 2 displays the median RTs for correct responses averaged across subjects for each condition of congruency, task and switch. A significant main effect of task $\left(F(1,16)=22.1, p<0.001, \eta^{2}=0.58\right)$ was observed, with faster responses when participants performed a semantic judgment. A significant effect of the switch $\left(F(1,16)=13.1, p<0.005, \eta^{2}=0.45\right)$ was also observed, with faster responses when two consecutive trials involved the same task. There was neither a main effect of prime congruency $\left(F(1,16)=0.27, p=0.6, \eta^{2}=0.017\right)$, nor a significant interaction with any other factor.

A similar analysis of response accuracy resulted in a significant main effect of switch $(\mathrm{F}(1,16)=13.6, \mathrm{p}<0.005)$. The overall accuracy level was high $(96.5 \%)$, indicating that participants performed the task properly.

< Insert Figure 2 about here >

\section{Experiment 2}

We found no task set priming in Experiment 1, when the stimulus onset asynchrony between the prime and the instruction was set at $36 \mathrm{~ms}$. In the experiment conducted by Lau and Passingham (2007), the task set priming was found when the SOA was $84 \mathrm{~ms}$, but not when it was $36 \mathrm{~ms}$, even though the prime was then conscious. These results suggest the interval between the prime and the instruction may be decisive for task set priming. In a second experiment, we used an interval similar to Lau and Passingham in their experiment (2007) to ascertain whether task set priming occurs in these conditions.

\subsection{Methods}


3.1.1 Participants. Twenty students from the University of Strasbourg (10 women, 10 men), aged from 23 to $30(\mathrm{M}=23.6, \mathrm{SD}=2.0)$, took part in the experiment. Their level of education ranged from 12 to 16 years $(\mathrm{M}=14.8, \mathrm{SD}=1.47)$. As in the previous experiment, all of the participants had normal or corrected-to-normal vision. They all took part in one 90minute session. Their informed written consent was obtained before the study in accordance with the recommendations set out in the Helsinki Declaration.

3.1.2 Experimental procedure. The only difference in relation to Experiment 1 was the time course of the mask and instruction letter as shown in Figure 1. To increase the SOA between prime and instruction, without modifying the masking procedure, the instruction appeared not in the same time as the mask, but $48 \mathrm{~ms}$ after the mask onset. The instruction duration (154 ms) was the same as in Experiment 1. The mask was displayed until the instruction offset. Thus, the SOA between prime and mask remained at $36 \mathrm{~ms}$, guaranteeing an excellent invisibility of the primes, but this time the SOA between prime and instruction letter was increased to $84 \mathrm{~ms}$. We also ensured there was a constant interval between the onsets of the prime and the target word by slightly shortening the blank separating the instruction and the word (Figure 1). As a result, the word appeared $344 \mathrm{~ms}$ after the prime, like in Experiment 1.

\subsection{Results}

3.2.1 Awareness of primes. Four subjects pointed out that bisyllabic words were inanimate or vice versa, leading them to respond always with a semantic task set and to reverse their response in the case of an "S" instruction. One participant's results were incoherent, with abnormally long and variable RTs (median RT=1265 ms, SD=690; compared to $727 \mathrm{~ms}$ and mean SD of 283 for the other 15 subjects). These five participants were excluded from the analyses. 
As in Experiment 1, none of the 15 participants reported having seen the prime letter before the target during the priming experiments. When told about the presence of the primes, 2 subjects said they thought they might have seen a slight blink but were unsure, and none thought it was a letter. Performance in the forced-choice task ranged from $42 \%$ to $60 \%$ and averaged $49.8 \%$, which was not significantly different from chance, $t(14)=-0.15, p=0.88$. The mean value of d' was 0.075 (not significantly different from $0: t(14)=0.784, p=0.45$ ). Mean accuracy for the 2 subjects who detected a flash was $49 \%$ and mean d' was -0.051 .

3.2.2 Repetition priming. The results of the repetition priming are presented in Figure 4. The ANOVA revealed a significant main effect of prime congruency $(F(1,14)=6.9$, $\left.\mathrm{p}<0.05, \eta^{2}=0.33\right)$ and switch $\left(\mathrm{F}(1,14)=8.2, \mathrm{p}<0.05, \eta^{2}=0.37\right)$. No significant interaction was observed between prime congruency and switch $\left(F(1,14)=0.028, p=0.87, \eta^{2}=0.002\right)$. Participants responded more quickly if the prime was the same as the instruction (437.6 ms) than if it was different (459.3). The mean extent of the priming effect was $21.7 \mathrm{~ms}$. Participants also responded faster if the instruction was the same rather than different for two consecutive trials (437.9 ms versus $456.2 \mathrm{~ms}$ ).

3.2.3 Task set priming. Figure 3 shows the median RTs for correct responses averaged across subjects for each condition in the task set priming procedure. A significant main effect of task $\left(F(1,14)=14.9, p<0.005, \eta^{2}=0.52\right)$ was observed, with faster responses when participants made a semantic judgment. A significant effect of the switch $(F(1,14)=15.2$, $\mathrm{p}<0.005, \eta^{2}=0.52$ ) was also observed, with faster responses when the same instruction was used for two consecutive trials. Crucially, we now observed a significant main effect of prime congruency $\left(F(1,14)=9.44, p<0.01, \eta^{2}=0.40\right)$, evidence that a subliminal prime identical to the conscious instruction produced a faster response than when the prime differed from the instruction. The only significant interaction was a switch-by-task interaction $(F(1,14)=8.76$, 
$\left.\mathrm{p}<0.05, \eta^{2}=0.38\right)$ : in the phonological task, the switch-related slowdown was more pronounced.

Accuracy was high (98.2\%), and no significant main effects or interaction were observed for response accuracy.

< Insert Figure 3 about here >

To check whether behavioral priming effects were greater in the case of participants who performed better in the prime visibility task, correlations were calculated between task set priming and prime identification performance. The correlations were based on the use of raw scores in the forced-choice task used to explore the awareness of primes on the one hand, and on the extent of task set priming, i.e. the difference between RTs for congruent and incongruent trials, in the different conditions of switch and task on the other hand. There were no significant correlations either for the whole group $(\mathrm{r}=-0.27, \mathrm{p}=0.33)$, or when the analyses included only the 8 participants whose prime identification performance was greater than 0.5 were included in the analyses $(\mathrm{r}=0.19, \mathrm{p}=0.66)$.

We conducted another correlation analysis, to check whether the repetition priming was correlated to the task set priming. The extent of task set priming was not correlated with that of repetition priming, i.e. the difference between RTs for congruent and incongruent trials during the repetition priming task $(\mathrm{r}=0.145, \mathrm{p}=0.61)$.

3.2.4 Comparison with Experiment 1. In order to compare the two experiments, we conducted ANOVAs with repeated measures with the same within-group factors, and with the experiment as a between-group factor. There was no significant difference between the mean 
accuracy or d' value in prime identification $\left(F(1.30)=0.008, p=0.93, \eta^{2}=0\right)$. However, in the repetition priming task, we observed a significant interaction between congruency and experiment $\left(F(1,30)=8.87, p<0.005, \eta^{2}=0.23\right)$. The repetition priming effect we observed was greater when the SOA prime-instruction was $36 \mathrm{~ms}$ rather than $84 \mathrm{~ms}$. The same analysis conducted on the task set priming task revealed a triple interaction between the experiment, congruency and switch factors $\left(F(1,30)=4.28, p<0.05, \eta^{2}=0.12\right)$. There was no other significant interaction involving the experiment factor. The significant interaction between the experiment, congruency and switch factors was decomposed by means of sub-analyses. The effect of congruency was significantly different across experiments in the no-switch condition, as shown by an ANOVA $\left(\mathrm{F}(1,30)=5.71, \mathrm{p}<0.05, \eta^{2}=0.16\right)$. The task set priming effect was greater in the no-switch condition for Experiment $2(24 \mathrm{~ms})$ than for Experiment 1 $(-8 \mathrm{~ms})$, i.e. when the SOA between prime and instruction was $84 \mathrm{~ms}$ rather than $36 \mathrm{~ms}$.

\section{Discussion}

The primary aim of the present study was to investigate whether control processes, and in particular those involved in establishing task sets, are modulated by unconscious stimuli. We explored this question in experimental conditions where a strong masking procedure ensured the prime was not consciously perceived, and where there were no trials involving conscious primes that attracted attention to their existence. The second aim was to clarify whether the task-set priming effect requires some delay before it can occur. The results showed that in strict experimental conditions (i) participants were faster to make a semantic/syllabic judgment when the instruction was preceded by a congruent prime in Experiment 2 but not in Experiment 1, and (ii) the prime congruency accelerated identification of the target letter in both experiments, but this repetition priming effect was greater in Experiment 1 than Experiment 2. 
Both subjective and objective measures showed that priming effects occurred in conditions where participants were not aware that a prime had been presented before the explicit cue telling them which task to perform. No participant reported having identified or even perceived a prime, and the d' resulting from the prime identification task were at chance level. Moreover, there was no correlation between the priming effect and the prime awareness. Taken together, these results suggest the task set priming effect observed in Experiment 2 does not arise from a minimal level of conscious prime perception by some of the participants in the study. However, it could be due to a repetition priming effect, which would mean that participants identify the instruction that has already been subliminally presented more quickly and thus they respond faster to the task instruction. If this were the case, faster reaction times would reflect perceptual priming rather than task set priming.

Before discussing this alternative, we shall first turn our attention to the differences in repetition priming effects observed between Experiment 1 and 2 and compare them to results previously reported in the literature.

Consistent with previous studies (Arguin \& Bub, 1995; Neumann \& Klotz, 1994), the subliminal primes were found to affect identification of the conscious instruction letter in the repetition priming procedure in both experiments, with shorter RTs when the prime was congruent, as opposed to incongruent, with the instruction. However, the extent of this repetition priming effect was greater in Experiment 1 than Experiment 2, when the lag between the prime and target was shorter (36 ms and $84 \mathrm{~ms}$ in Experiment 1 and 2, respectively). The suggestion is that the repetition priming effect dwindles over time. In a word naming task, Ferrand (1996) also showed that the masked repetition priming effect dissipated when the prime-target interval increased. However, this decrease occurred with prime-target intervals of $500 \mathrm{~ms}$ and $1000 \mathrm{~ms}$ whereas the priming effect remained strong with $50 \mathrm{~ms}$ and $150 \mathrm{~ms}$ intervals. With shorter intervals, in the range of those used in the 
present study, Vorberg et al. (2003) reported a heightening of the priming effect when the prime-target interval increased. It is to be noted, however, that they used a metacontrast masking in which the mask is also the target. The increase in the prime-target interval was therefore associated with an increase in the delay between the prime and the mask, which could have induced deeper processing of the prime. Indeed, according to Vorberg et al., even if the participants were never able to accurately discriminate the shape from the prime, as the prime-mask interval increased they became better at detecting the presence of a prime. Other studies that used prime-target intervals as short as those used in the present experiments reported results consistent with our findings. For example, Lignau and Vorberg (2005), used a masked priming task in which the interval between the prime and the mask remained constant (70 ms) and showed that the priming effect decreased when the prime-target SOA increased from $70 \mathrm{~ms}$ to $154 \mathrm{~ms}$. Schlaghecken and Eimer (1997) observed the same tendency with pattern masking, when the prime and the target were peripheral. The decrease in the repetition priming effect between our two experiments could also be related to differences in the mask duration, which was longer in Experiment 2 (200 ms) than in Experiment 1 (152 ms) (Hashimoto et al., 2006).

Whatever the explanation for the changes in the repetition priming effect depending on the prime-target SOA, an important finding from our study was the dissociation between the repetition priming effect and the task set priming effect. When the prime-instruction interval increased from $36 \mathrm{~ms}$ to $84 \mathrm{~ms}$, the repetition priming effect decreased whereas the task set priming effect increased (Figure 4). This dissociation argues against the hypothesis that these two priming effects are subtended by the same mechanism. It is further supported by the lack of correlation between the repetition priming effect and the task set priming effect, the suggestion being that faster identification of the letter induced by the prime was not a determining factor in the task set priming. To sum up, our findings from Experiments 1 and 2 
are evidence that task set activation can be affected by a prime that participants do not consciously perceive, independently of a possible perceptual repetition priming effect. This conclusion is consistent with a study conducted by Reuss et al. (2011) which showed that a task set can be activated by subliminal information even when perceptual priming of the task cue cannot take place. In their study, Reuss et al. dropped the prime and manipulated the visibility of the task cue so that participants consciously perceived it in some trials but not in others. Stimuli were one-digit numbers. Task cues (w or b) indicated to participants that they were to perform either a parity task (odd or even) or a magnitude task (less or greater than 5). When cues were rendered invisible, subjects were instructed to choose freely which task they carried out. The results showed that even when they were not aware of the task cue, participants chose the cued task more often than the non-cued task and performed it more quickly.

\section{< Insert Figure 4 about here >}

The task set priming effect occurred in Experiment 2 but not in Experiment 1. Participants were equally unaware of the presence of a prime in both experiments, which means the explanation cannot reside in differences in conscious perception of the prime from one experiment to the next. In contrast, the time between the onset of the prime and the onset of the instruction increased from $36 \mathrm{~ms}$ to $84 \mathrm{~ms}$ between Experiments 1 and 2. Mattler (2003) showed that priming of cognitive control operations did not occur when the prime-cue SOA was set at $34 \mathrm{~ms}$ or $51 \mathrm{~ms}$ but increased linearly when the SOA increased from $68 \mathrm{~ms}$ to $119 \mathrm{~ms}$. Taken together, these findings suggest the time interval between the prime and the task cue has to be long enough to allow a task set priming. This interpretation is also consistent with the results obtained by Lau and Passingham, which showed no task set 
priming effect when the prime was consciously perceived but the delay between the prime and the instruction was as short as $16 \mathrm{~ms}$.

We have to consider a limitation to this interpretation which stems from differences across our two experiments in the interval between the consciously perceived instruction letter and the word to be processed. When the SOA between prime and instruction letter increased from $36 \mathrm{~ms}$ to $84 \mathrm{~ms}$, the interval between the instruction letter and the word changed in the opposite direction (308 ms in Experiment 1 versus $260 \mathrm{~ms}$ in Experiment 2). Therefore, the possibility that the task priming effect also occurred in Experiment 1 but then dissipated because the word occurred later relative to when the task instruction was presented cannot be ruled out. In Lau and Passingham (2007), however, the interval between the instruction and the word remained constant even when the interval between the prime and the instruction changed. Thus, this second explanation cannot account for the absence of a task priming effect in their short prime-instruction condition. Consequently, it seems unlikely that a decrease in the instruction-word interval is the sole explanation for all of our results. Our own data also suggest otherwise. When the interval between the instruction letter and the word is shorter, there is less time to initiate the task set. This could explain the greater influence of the unconscious prime in Experiment 2. However, if the instruction-word delay is crucial, the task set priming effect should be greater when the task set is the most difficult to initiate after the instruction. In fact, difficulty initiating the task set should reduce the instruction-word delay still further. In our case, this situation is typical of the phonological task: to count the number of syllables when reading is not a natural task. The task set should be even more difficult in the switch condition, i.e. when the phonological task has to be initiated after a semantic task trial, but, in reality, the results are not consistent with this prediction. On the contrary, they show that the task set priming tends to be greater when the instruction-induced task setting is 
the easiest, i.e. in the repeated (no switch) trials and in the semantic task. This suggests the instruction-word delay is not the key factor.

The task set priming effect we observed was small (15 ms) and, in particular, smaller than the effect reported by Lau and Passingham (2007), which they estimated at $100 \mathrm{~ms}$. Even if the priming effect reported by Mattler (2003), $45 \mathrm{~ms}$, is more similar to our own, the difference in relation to the effect found by Lau and Passingham is important. The first explanation for it could be that in Lau and Passingham study participants were not completely unaware of the presentation of the prime since their d' measurements were higher than ours. The attention the participants gave the primes could be another critical factor. In our paradigm, they were not told about the presence of primes until the end of the task set priming experiment and, in contrast to the study conducted by Lau and Passingham, there were no trials with conscious primes. It has previously been shown that attention can influence the effect of unconscious primes (Greenwald, Abrams, Naccache, \& Dehaene, 2003; Naccache et al., 2002). For instance, Naccache et al. (2002) showed that unattended primes might fail to elicit priming effects. Therefore, it could be argued that the presence of trials in which primes were perceived consciously, as in the study by Lau and Passingham, caused participants to attend to the primes, and thus yielded larger priming effects than in the present study.

Importantly, in our experiments, participants were trained and prepared to perform frequent task switching. The prime may thus have prompted them to switch between two task sets which were simultaneously active. In other words, the prime may not have triggered the whole preparation of a task set, but merely the choice whether or not to initiate a task switch (Meiran, 2000). Cognitive control has been modeled as consisting of several nested components, with the frontal cortex organized functionally as a cascade of control processes (Koechlin, Ody, \& Kouneiher, 2003). The higher level is related to episodic control, which enables the subject to establish new task sets, according to previous events or ongoing internal 
goals. Because both task sets were already consciously prepared, and indeed perhaps routinized, this level would not be the one activated subliminally in our paradigm. Instead, our paradigm would implement a contextual control stage (Koechlin et al., 2003). The unconscious task set priming we observed might be related to the selection of one of the two task sets already activated. This suggests the need to split cognitive control into distinct components differentially related to conscious processing. While task set and goal changing decisions may be partially initiated subliminally, the present results leave open the question of whether other cognitive control operations are influenced by unconscious stimuli.

\section{Conclusion}

Our results confirmed that unconscious task set priming is possible for high level cognitive processes. By controlling unconscious conditions better, with a shorter prime, we were able to reproduce and extend the results obtained by Lau and Passingham (2007). The extent of our task set priming was smaller but significant. In future, it would be useful to combine our paradigm with high temporal resolution cerebral recordings in order to identify the precise neural mechanisms of task set priming. Even if our findings confirm the existence of an unconscious modulation of cognitive control, it remains to be seen whether all prefrontal cognitive control systems can be activated unconsciously, without concomitant conscious control. 


\section{References}

Arguin, M., \& Bub, D. (1995). Priming and Response Selection Processes in Letter Classification and Identification Tasks. Journal of Experimental Psychology: Human Perception and Performance, 21(5), 1199-1219.

Bach, M. (2006). The Freiburg Visual Acuity Test-Variability unchanged by post-hoc reanalysis. Graefe's Archive for Clinical and Experimental Ophthalmology, 245(7), 965971. doi:10.1007/s00417-006-0474-4

Bijleveld, E., Custers, R., \& Aarts, H. (2010). Unconscious reward cues increase invested effort, but do not change speed-accuracy tradeoffs. Cognition, 115(2), 330-335. doi:10.1016/j.cognition.2009.12.012

Bijleveld, E., Custers, R., \& Aarts, H. (2012). Adaptive Reward Pursuit: How Effort Requirements Affect Unconscious Reward Responses and Conscious Reward Decisions. Journal of experimental psychology. General. doi:10.1037/a0027615

Binsted, G., Brownell, K., Vorontsova, Z., Heath, M., \& Saucier, D. (2007). Visuomotor system uses target features unavailable to conscious awareness. Proceedings of the National Academy of Sciences, 104(31), 12669 -12672. doi:10.1073/pnas.0702307104

Capa, R. L., Bouquet, C. A., Dreher, J.-C., \& Dufour, A. (2012). Long-lasting effects of performance-contingent unconscious and conscious reward incentives during cued taskswitching. Cortex. doi:10.1016/j.cortex.2012.05.018

Dehaene, S., \& Changeux, J.-P. (2011). Experimental and theoretical approaches to conscious processing. Neuron, 70(2), 200-227. doi:10.1016/j.neuron.2011.03.018

Dehaene, S., Changeux, J.-P., Naccache, L., Sackur, J., \& Sergent, C. (2006). Conscious, preconscious, and subliminal processing: a testable taxonomy. Trends in Cognitive Sciences, 10(5), 204-211. doi:10.1016/j.tics.2006.03.007

Dehaene, S., \& Naccache, L. (2001). Towards a cognitive neuroscience of consciousness: basic evidence and a workspace framework. Cognition, 79(1-2), 1-37.

Del Cul, A., Baillet, S., \& Dehaene, S. (2007). Brain dynamics underlying the nonlinear threshold for access to consciousness. PLoS Biology, 5(10), e260. doi:10.1371/journal.pbio.0050260

Del Cul, A., Dehaene, S., \& Leboyer, M. (2006). Preserved subliminal processing and impaired conscious access in schizophrenia. Archives of General Psychiatry, 63(12), 1313-1323. doi:10.1001/archpsyc.63.12.1313

Ferrand, L. (1996). The masked repetition priming effect dissipates when increasing the interstimulus interval: Evidence from word naming. Acta Psychologica, 91(1), 15-25. doi:10.1016/0001-6918(95)00010-0

Francis, G. (1997). Cortical dynamics of lateral inhibition: Metacontrast masking. Psychological Review, 104(3), 572-594.

Gaillard, R., Del Cul, A., Naccache, L., Vinckier, F., Cohen, L., \& Dehaene, S. (2006). Nonconscious semantic processing of emotional words modulates conscious access. Proceedings of the National Academy of Sciences of the United States of America, 103(19), 7524-7529. doi:10.1073/pnas.0600584103

Greenwald, A. G., Abrams, R. L., Naccache, L., \& Dehaene, S. (2003). Long-term semantic memory versus contextual memory in unconscious number processing. Journal of Experimental Psychology. Learning, Memory, and Cognition, 29(2), 235-247. doi:10.1037/0278-7393.29.2.235

Hashimoto, A., Watanabe, S., Inui, K., Hoshiyama, M., Murase, S., \& Kakigi, R. (2006). Backward-masking: the effect of the duration of the second stimulus on recognition of 
the first stimulus. Neuroscience, 137(4), 1427-1437.

doi:10.1016/j.neuroscience.2005.10.047

Hughes, G., Velmans, M., \& Fockert, J. D. (2009). Unconscious priming of a no-go response. Psychophysiology, 46(6), 1258-1269. doi:10.1111/j.1469-8986.2009.00873.x

Koechlin, E., Ody, C., \& Kouneiher, F. (2003). The Architecture of Cognitive Control in the Human Prefrontal Cortex. Science, 302(5648), 1181-1185. doi:10.1126/science.1088545

Kouider, S., \& Dehaene, S. (2007). Levels of processing during non-conscious perception: a critical review of visual masking. Philosophical Transactions of the Royal Society B: Biological Sciences, 362(1481), 857-875. doi:10.1098/rstb.2007.2093

Lau, H. C., \& Passingham, R. E. (2007). Unconscious activation of the cognitive control system in the human prefrontal cortex. The Journal of Neuroscience, 27(21), 5805-5811. doi:10.1523/JNEUROSCI.4335-06.2007

Lingnau, A., \& Vorberg, D. (2005). The time course of response inhibition in masked priming. Perception \& Psychophysics, 67(3), 545-557.

Mattler, U. (2003). Priming of mental operations by masked stimuli. Perception \& psychophysics, 65(2), 167-187.

Meiran, N. (2000). Modeling cognitive control in task-switching. Psychological Research, 63(3-4), 234-249.

Merikle, P. M., Joordens, S., \& Stolz, J. A. (1995). Measuring the relative magnitude of unconscious influences. Consciousness and Cognition, 4(4), 422-439. doi:10.1006/ccog. 1995.1049

Naccache, L., Blandin, E., \& Dehaene, S. (2002). Unconscious masked priming depends on temporal attention. Psychological Science, 13(5), 416-424.

Naccache, L., \& Dehaene, S. (2001). Unconscious semantic priming extends to novel unseen stimuli. Cognition, 80(3), 215-229.

Neumann, O., \& Klotz, W. (1994). Motor responses to nonreportable, masked stimuli: Where is the limit of direct parameter specification. In C. Umiltà (éd.), Attention and performance $X V$ : Conscious and nonconscious information processing (p. 123-150). Cambridge, Mass.: MIT Press.

New, B., Pallier, C., Ferrand, L., \& Matos, R. (2001). Une base de données lexicales du français contemporain sur internet: LEXIQUE ${ }^{\mathrm{TM}} / / \mathrm{A}$ lexical database for contemporary french: LEXIQUE ${ }^{\mathrm{TM}}$. L'année psychologique, 101(3), 447-462.

Pessiglione, M., Schmidt, L., Draganski, B., Kalisch, R., Lau, H., Dolan, R. J., \& Frith, C. D. (2007). How the Brain Translates Money into Force. Science (New York, N.Y.), 316(5826), 904-906. doi:10.1126/science.1140459

Reuss, H., Kiesel, A., Kunde, W., \& Hommel, B. (2011). Unconscious activation of task sets. Consciousness and Cognition. doi:10.1016/j.concog.2011.02.014

Rogers, R., \& Monsell, S. (1995). Costs of a predictable switch between simple cognitive tasks. Journal of Experimental Psychology. General, 124(2), 207-230.

Schlaghecken, F., \& Eimer, M. (1997). The influence of subliminally presented primes on response preparation. Sprache \& Kognition, 16(3-4), 166-175.

Schmidt, T., \& Vorberg, D. (2006). Criteria for unconscious cognition: three types of dissociation. Perception \& Psychophysics, 68(3), 489-504.

Stoerig, P., \& Cowey, A. (1997). Blindsight in man and monkey. Brain: A Journal of Neurology, 120 ( Pt 3), 535-559.

Van den Bussche, E., Notebaert, K., \& Reynvoet, B. (2009). Masked primes can be genuinely semantically processed: a picture prime study. Experimental psychology, 56(5), 295-300. doi:10.1027/1618-3169.56.5.295 
Van den Bussche, E., \& Reynvoet, B. (2007). Masked priming effects in semantic categorization are independent of category size. Experimental psychology, 54(3), 225235.

Van den Bussche, E., Segers, G., \& Reynvoet, B. (2008). Conscious and unconscious proportion effects in masked priming. Consciousness and Cognition, 17(4), 1345-58. doi:10.1016/j.concog.2007.08.005

Van Gaal, S., Ridderinkhof, K. R., Fahrenfort, J. J., Scholte, H. S., \& Lamme, V. A. F. (2008). Frontal cortex mediates unconsciously triggered inhibitory control. The Journal of Neuroscience, 28(32), 8053-8062. doi:10.1523/JNEUROSCI.1278-08.2008

Van Gaal, S., Ridderinkhof, K. R., Scholte, H. S., \& Lamme, V. A. F. (2010). Unconscious activation of the prefrontal no-go network. The Journal of Neuroscience, 30(11), 41434150. doi:10.1523/JNEUROSCI.2992-09.2010

Vangkilde, S., Coull, J. T., \& Bundesen, C. (2012). Great expectations: Temporal expectation modulates perceptual processing speed. Journal of experimental psychology. Human perception and performance. doi:10.1037/a0026343

Vorberg, D., Mattler, U., Heinecke, A., Schmidt, T., \& Schwarzbach, J. (2003). Different time courses for visual perception and action priming. Proceedings of the National Academy of Sciences of the United States of America, 100(10), 6275-6280. doi:10.1073/pnas.0931489100

Whalen, P. J., Rauch, S. L., Etcoff, N. L., McInerney, S. C., Lee, M. B., \& Jenike, M. A. (1998). Masked Presentations of Emotional Facial Expressions Modulate Amygdala Activity without Explicit Knowledge. The Journal of Neuroscience, 18(1), 411-418. 


\section{Footnotes}

${ }^{1}$ Although the formulation in Dehaene \& Naccache (2001) is ambiguous, the workspace model does not preclude rule out the possibility that automatic bottom-up effects of an unconscious stimulus T1 may bias the choice of a cognitive strategy applied, in turn, to a second target $\mathrm{T} 2$. What is ruled out is that an unconscious stimulus $\mathrm{T} 1$ changes the strategy applied to itself, as this would imply a closed bottom-up and top-down loop, which, in the global neuronal workspace model, is deemed to imply reverberating ignition and therefore conscious perception. Thus, the present data do not strictly imply rejection of the global workspace model. 


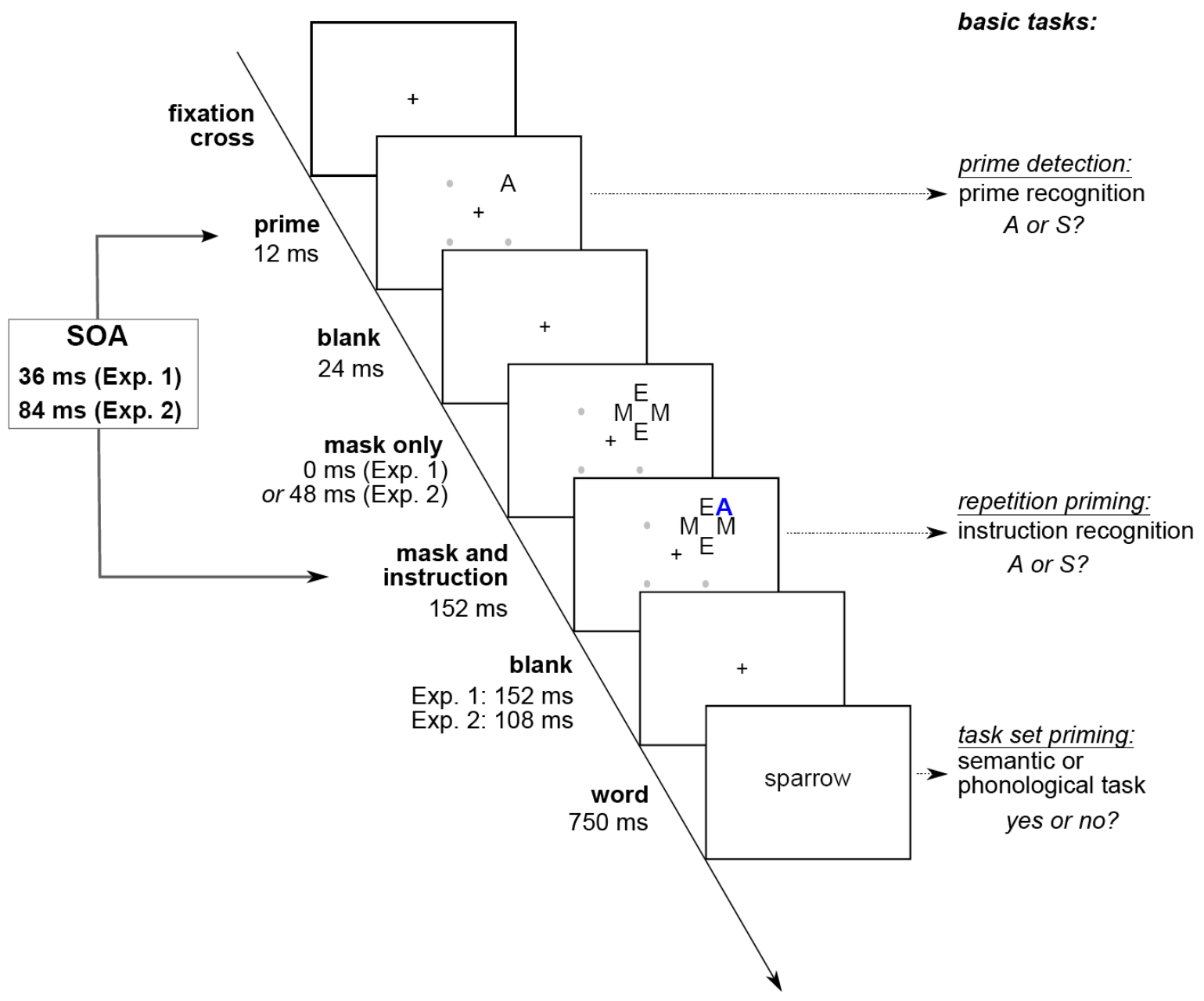

Figure 1. Stimuli and procedure of Experiments 1 and 2. The stimuli consisted of a prime letter (A or S), masked by the next four letters, the instruction letter (A or S), and then the word. The prime was congruent or incongruent with the instruction letter. The two experiments differed in the interval between the prime and the instruction letter. The participants performed three tasks in succession (in three blocks). First, they performed the "task set priming" task, in which they had to make either a phonological judgment (bisyllabic or not) or semantic judgment (animate/inanimate) on the following word, according to the instruction letter. Then, they performed the "repetition priming" task, in which they had to identify the instruction letter, and, then, finally, they attempted to identify the prime letter, so that we could check whether or not they were aware of the prime ("prime detection"). 

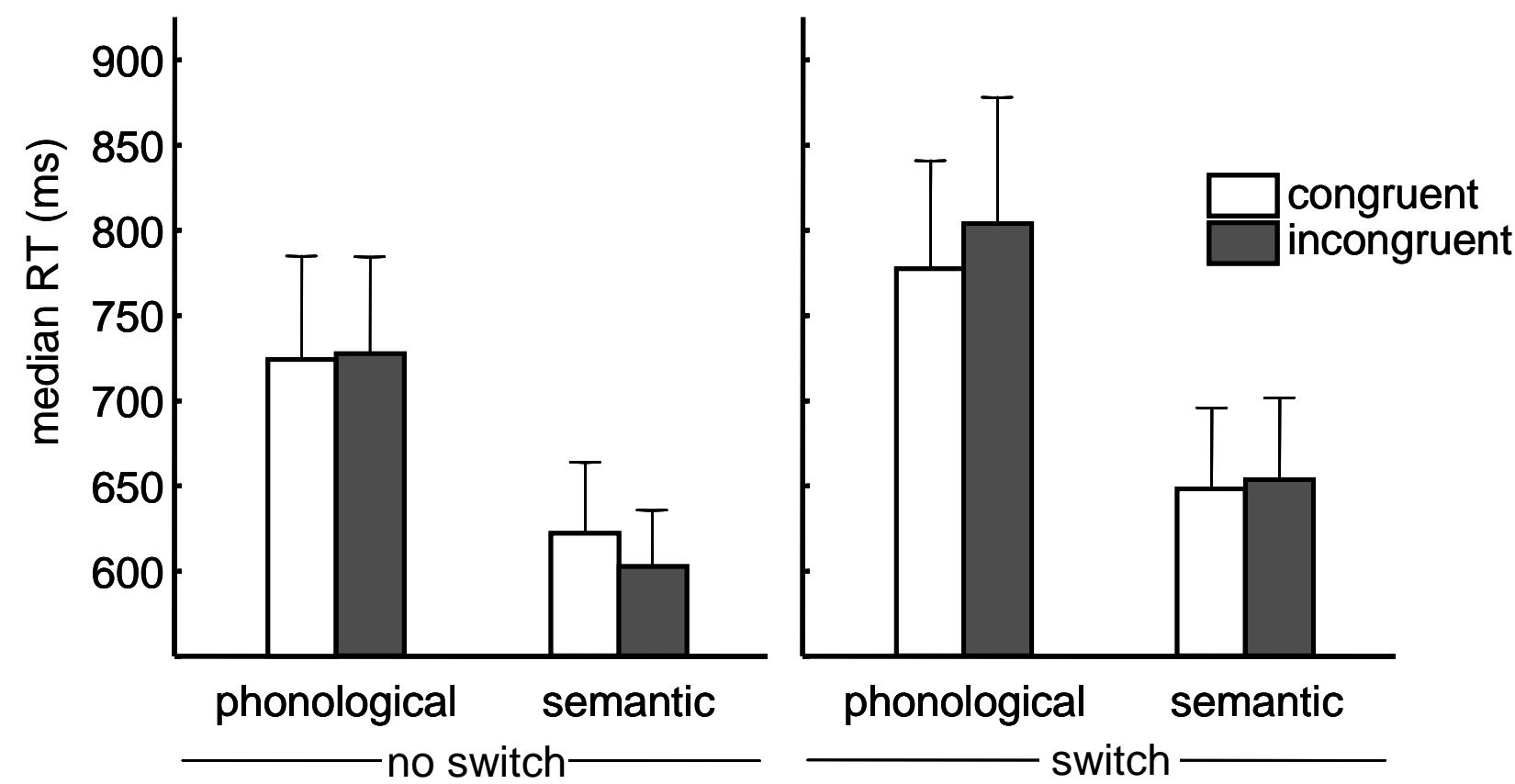

Figure 2. Median response time for correct responses (in ms) averaged across subjects in the task set priming procedure in Experiment 1 (prime-instruction SOA=36ms) (17 subjects). The results are displayed as a function of whether task switching occurred relative to the previous trial, of the type of task, and of congruency of the prime with the explicit instruction. Vertical bars denote +/- standard errors.

A main effect of task type $(p<0.001)$ and a main effect of the switch $(p<0.005)$ were observed. However, there was no significant difference in response times between when the subliminal prime was congruent and when it was incongruent with the explicit instruction. 

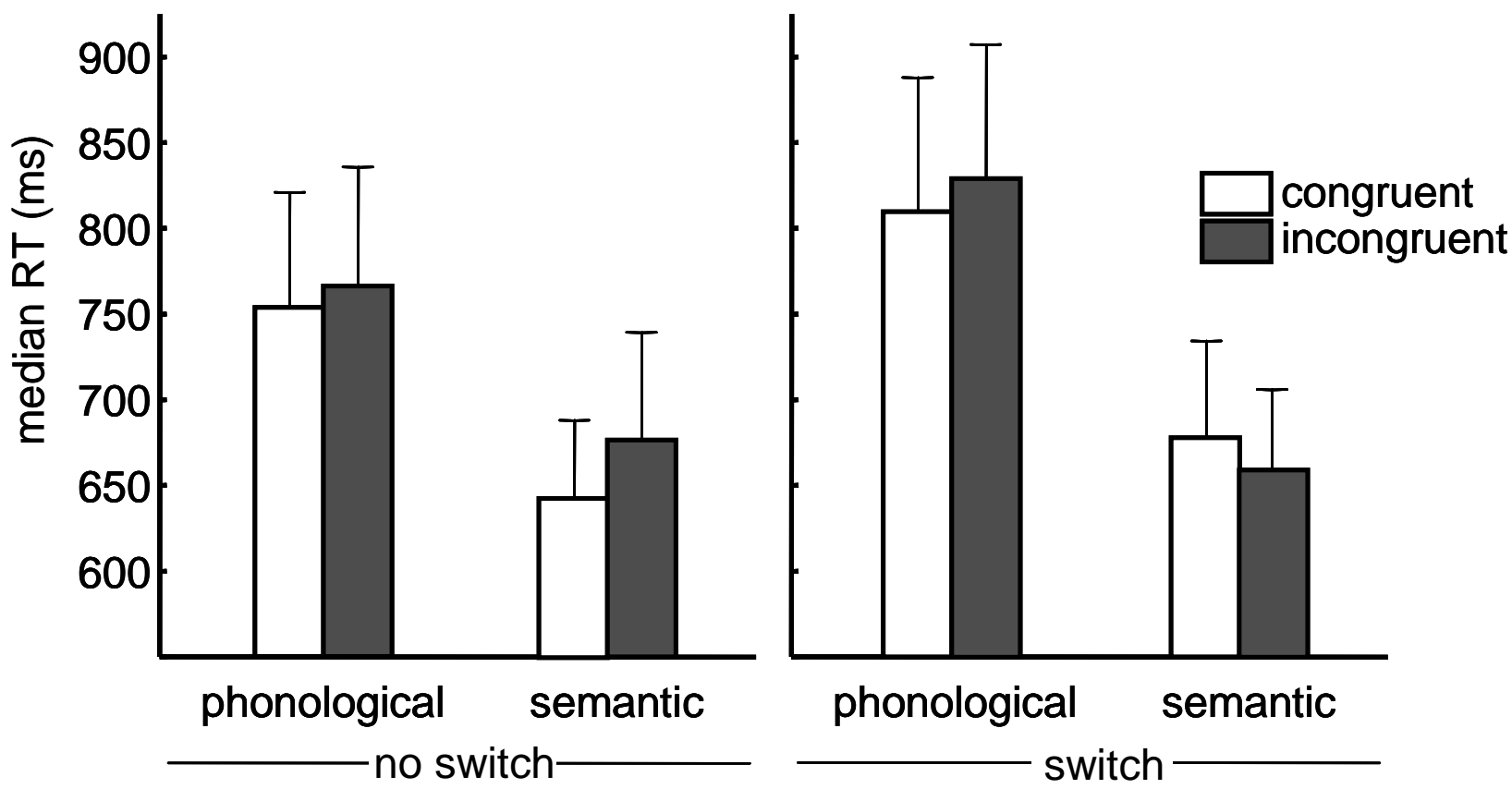

Figure 3. Median response time for correct responses (in ms) averaged across subjects in the task set priming procedure in Experiment 2 (prime-instruction $\mathrm{SOA}=84 \mathrm{~ms}$ ) (15 subjects). Same format as Figure 2.

A main effect of task set type $(\mathrm{p}<0.005)$ and a main effect of the switch $(\mathrm{p}<0.005)$ were observed, as in Experiment 1. Moreover, there was a significant reduction in response times when the subliminal prime was congruent with the explicit instruction, relative to the incongruent condition $(\mathrm{p}<0.01)$. 


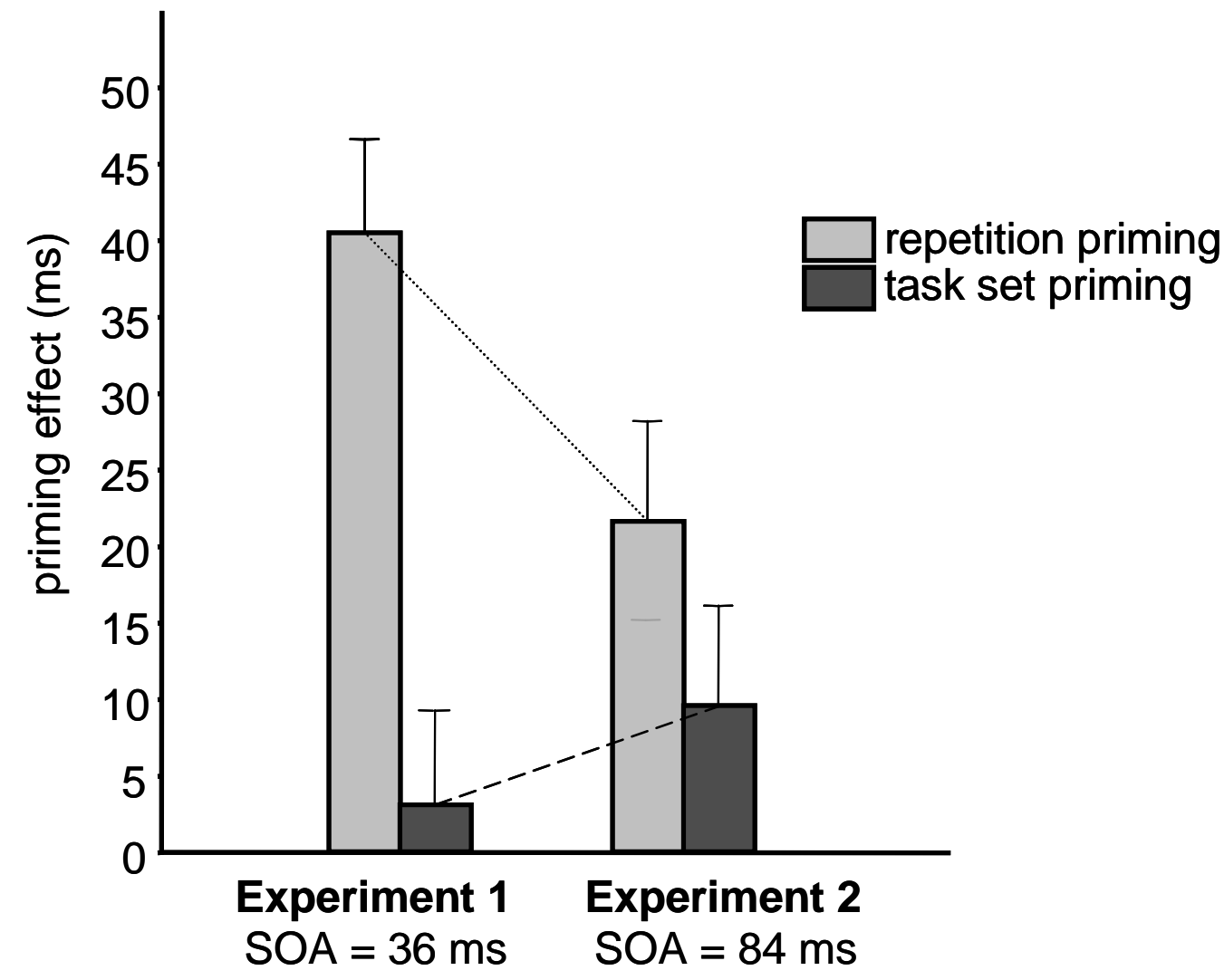

Figure 4. Comparison of the priming effect (incongruent RT - congruent RT) for the repetition priming procedure and the task set priming procedure between Experiments 1 $(\mathrm{SOA}=36 \mathrm{~ms})$ and $2(\mathrm{SOA}=84 \mathrm{~ms})$. As the prime-instruction stimulus onset asynchrony (SOA) lengthens from $36 \mathrm{~ms}$ to $84 \mathrm{~ms}$, the repetition priming effect decreases, whereas the task set priming increases. 